Journal of Advanced Research in Fluid Mechanics and Thermal Sciences

Journal homepage: www.akademiabaru.com/arfmts.html ISSN: 2289-7879

\title{
Stability Analysis of Unsteady Hybrid Nanofluid Flow Past a Permeable Stretching/Shrinking Cylinder
}

\author{
Nurul Amira Zainal ${ }^{1,2,}{ }^{,}$, Roslinda Nazar ${ }^{1}$, Kohilavani Naganthran ${ }^{1}$, Ioan Pop ${ }^{3}$ \\ 1 Department of Mathematical Sciences, Faculty of Science and Technology, Universiti Kebangsaan Malaysia, 43600 UKM Bangi, Selangor, \\ Malaysia \\ 2 Fakulti Teknologi Kejuruteraan Mekanikal dan Pembuatan, Universiti Teknikal Malaysia Melaka, Hang Tuah Jaya, 76100 Durian Tunggal, Melaka, \\ Malaysia \\ 3 Department of Mathematics, Babeş-Bolyai University, R-400084 Cluj-Napoca, Romania
}

\section{ARTICLE INFO}

\section{Article history:}

Received 24 April 2021

Received in revised form 5 July 2021

Accepted 10 July 2021

Available online 13 August 2021

\section{Keywords:}

Stability analysis; unsteady flow; hybrid nanofluid; stretching/shrinking cylinder; dual solutions

\section{ABSTRACT}

The study of boundary layer flow has gained considerable interest owing to its extensive engineering applications. Thus, this numerical study aims to develop a mathematical hybrid nanofluid model and perform a stability analysis of unsteady flow in the hybrid $\mathrm{Al}_{2} \mathrm{O}_{3}-\mathrm{Cu} / \mathrm{H}_{2} \mathrm{O}$ nanofluid past a permeable stretching/shrinking cylinder. The partial differential equations are converted into a system of nonlinear ordinary differential equations by selecting suitable similarity transformation and solved using the bvp4c code in the MATLAB program. The findings revealed that the existence of dual solutions is visible and successfully disclosed the fluid flow separation points. The skin friction coefficient and the local Nusselt numbers of $\mathrm{Al}_{2} \mathrm{O}_{3}-\mathrm{Cu} / \mathrm{H}_{2} \mathrm{O}$ increase with the inclusion of the suction parameter, which consequently boosts the heat transfer efficiency. The coefficient of skin friction over the permeable stretching/shrinking cylinder is reduced when the unsteadiness parameter is diminished. In addition, the presence of the unsteadiness parameter actively promotes heat transfer degradation on the permeable stretching/shrinking cylinder. Stability analysis indicates that a stable and physically realizable solution appeared in the first solution, whereas the second solution is unstable.

\section{Introduction}

In recent decades, conventional heat transfer fluids such as ethylene glycol mixture, water, and mineral oil are considered poor heat transfer fluids. It is also well understood that the thermal conductivity of such fluids performs a major role in the coefficient of heat transfer. Consequently, Choi and Eastman [1] developed a genius idea of nanofluid to provide better thermal conductivity compared to conventional fluids. Later on, an innovative type of nanofluid, for example, hybrid nanofluid, is now being adopted to support the necessary heat-conducting processes. This modern form of working fluid has attracted many researchers. The effect of thermal conductivity between nanofluids and hybrid nanofluids was assessed by Das [2], while Hamzah et al., [3] concluded that

\footnotetext{
${ }^{*}$ Corresponding author.

E-mail address: nurulamira@utem.edu.my
}

https://doi.org/10.37934/arfmts.86.1.6475 
the hybrid nanofluid's efficiency is usually defined by its dispersion's stability, volume concentration, and mixing ratios. Numerous studies have been performed on various aspects of hybrid nanofluids [4-9].

Earlier studies indicated that the unsteady flow activity exhibits an odd pattern instead of the steady flow due to the different time-based conditions, which distorted boundary layer distinction and fluid motion structure [10-11]. Nevertheless, with an inclusive understanding of the unsteady flow application in engineering practices, the new design approaches that facilitate system performance, reliability, and cost reduction of many fluids dynamic devices are feasible [12]. TieGang et al., [13] examined the unsteady viscous flow toward an expanding stretching cylinder, Ramesh et al., [14] performed a numerical analysis of unsteady contracting cylinder in nanofluid with magnetic effect, while Tabassum et al., [15] presented multiple solutions in an unsteady stretching cylinder.

According to Ganesan and Loganathan [16], the study of fluid flow toward a cylinder is crucial and essential to the industries, especially inflow prediction, heat transfer, and pollutant diffusion about invasive bodies, particularly piping intrusions of a magnet, casting procedures, and salt domes. Buchlin [17] reported that the curvature of the cylinder and its misalignment with the main flow has a significant influence on convective heat transfer. Datta et al., [18] and Kumari and Nath [19] testified that the suction/injection effect toward a thin cylinder might be useful in the nuclear reactors cooling process during a power outage where a coolant is injected to cool the surface. Some available literature on the flow of a deformable cylinder can be assessed through [20-24].

The goal of the current work is to fulfil the research gap on the previous literature, specifically in the study of boundary layer flow toward the stretching/shrinking cylinder. The major contribution in performing this numerical research is the successful development of a mathematical hybrid nanofluid model past an unsteady flow in $\mathrm{Al}_{2} \mathrm{O}_{3}-\mathrm{Cu} / \mathrm{H}_{2} \mathrm{O}$ past a permeable shrinking/stretching cylinder. Also, the presence of dual solutions is identified; hence a stability analysis is performed to observe the solutions' reliability. The bvp4c code in the MATLAB system is utilised to execute the numerical computations. The new findings are substantially in line with prior literature. This research is unique, and all numerical results obtained are original. In addition, this significant contribution may help to better understand and improve industrial development, especially in the manufacturing and process sectors.

\section{Mathematical Formulation}

An unsteady hybrid nanofluid flow past a permeable stretching/shrinking cylinder is analysed. Figure 1 demonstrates the schematic problem flow where $(x, r)$ is the coordinate system, and the working fluid is supposed to flow in the $x$-axis while the $r$-coordinate is normal to it. We also claimed that the deformable (stretching/shrinking) circular cylinder has a constant radius, $a$ and consists of linear velocity, $U_{w}(x)$ with uniform characteristic velocity, $u_{0}$ where $U_{w}(x)=u_{0} x / L(1-\beta t)$ . Besides, the constant mass flux is indicated by $v_{w}(r)$, thus $v_{w}(r)<0$ and $v_{w}(r)>0$ signify the suction and injection conditions, respectively. From the above assumptions, it is possible to describe the governing boundary layer equations as such [21-25]

$$
\frac{\partial(r u)}{\partial x}+\frac{\partial(r v)}{\partial r}=0
$$




$$
\begin{aligned}
& \frac{\partial u}{\partial t}+u \frac{\partial u}{\partial x}+v \frac{\partial u}{\partial r}=\frac{\mu_{h n f}}{\rho_{h n f}}\left(\frac{\partial^{2} u}{\partial r^{2}}+\frac{1}{r} \frac{\partial u}{\partial r}\right), \\
& \frac{\partial T}{\partial t}+u \frac{\partial T}{\partial x}+v \frac{\partial T}{\partial r}=\frac{k_{h n f}}{\left(\rho C_{p}\right)_{h n f}}\left(\frac{\partial^{2} T}{\partial r^{2}}+\frac{1}{r} \frac{\partial T}{\partial r}\right),
\end{aligned}
$$

and the boundary conditions are

$$
\begin{gathered}
u=\lambda U_{w}(x), v=v_{w}(r), T=T_{w}(x), \text { at } r=a, \\
u \rightarrow 0, T \rightarrow T_{\infty} \text { as } r \rightarrow \infty .
\end{gathered}
$$

At this point, $u$ and $v$ are the velocity components of $\mathrm{Al}_{2} \mathrm{O}_{3}-\mathrm{Cu} / \mathrm{H}_{2} \mathrm{O}$ involving $x-$ and $r$ - axis, respectively, $T$ is the temperature, $\mu_{h n f}$ is the dynamic viscosity, $k_{h n f}$ is the thermal conductivity, $\left(\rho C_{p}\right)_{h n f}$ is the heat capacity, while $\rho_{h n f}$ is the density of $\mathrm{Al}_{2} \mathrm{O}_{3}-\mathrm{Cu} / \mathrm{H}_{2} \mathrm{O}$. It is assumed that $T_{w}(x)=\left(T_{\infty}+T_{0}(x / L)^{2}\right) /(1-\beta t)^{2}$, where $T_{0}$ is the characteristic temperature and $L$ is the characteristic length. The parameter of stretching/shrinking is symbolised by $\lambda$ with $\lambda>0$ and $\lambda<0$ represent stretching and shrinking cylinder, respectively, while $\lambda=0$ indicated a rigid cylinder. Further, Table 1 offers the nanoparticles' thermophysical properties of $\mathrm{H}_{2} \mathrm{O}, \mathrm{Al}_{2} \mathrm{O}_{3}$, and $\mathrm{Cu}$, as demonstrated by $\mathrm{Abu}$ Nada and Oztop [26]. Meanwhile, the correlation coefficient of $\mathrm{Al}_{2} \mathrm{O}_{3}-\mathrm{Cu} / \mathrm{H}_{2} \mathrm{O}$ described by Ghalambaz et al., [27] and Takabi and Salehi [28] is presented in Table 2.

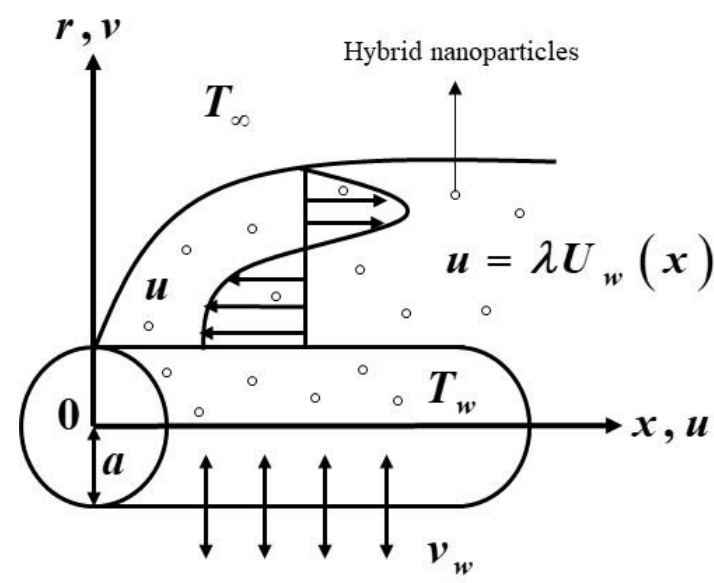

Fig. 1. The schematic problem flow of permeable shrinking cylinder

Table 1

The $\mathrm{H}_{2} \mathrm{O}, \mathrm{Al}_{2} \mathrm{O}_{3}$ and $\mathrm{Cu}$ thermophysical properties [26]

\begin{tabular}{llll}
\hline Physical properties & $\mathrm{H}_{2} \mathrm{O}$ & $\mathrm{Al}_{2} \mathrm{O}_{3}$ & $\mathrm{Cu}$ \\
\hline$\rho\left(\mathrm{kg} / \mathrm{m}^{3}\right)$ & 997.1 & 3970 & 8933 \\
$C_{p}(\mathrm{~J} / \mathrm{kgK})$ & 4179 & 765 & 385 \\
$k(\mathrm{~W} / \mathrm{mK})$ & 0.613 & 40 & 400 \\
\hline
\end{tabular}




\section{Table 2}

The alumina-copper/water $\left(\mathrm{Al}_{2} \mathrm{O}_{3}-\mathrm{Cu} / \mathrm{H}_{2} \mathrm{O}\right)$ correlation coefficient $[27,28]$

\begin{tabular}{ll}
\hline Properties & $\mathrm{Al}_{2} \mathrm{O}_{3}-\mathrm{Cu} / \mathrm{H}_{2} \mathrm{O}$ \\
\hline Density & $\rho_{h n f}=\left(1-\phi_{h n f}\right) \rho_{f}+\phi_{1} \rho_{s 1}+\phi_{2} \rho_{s 2}$ \\
Thermal capacity & $\left(\rho C_{p}\right)_{h n f}=\left(1-\phi_{h n f}\right)\left(\rho C_{p}\right)_{f}+\phi_{1}\left(\rho C_{p}\right)_{s 1}+\phi_{2}\left(\rho C_{p}\right)_{s 2}$ \\
Dynamic viscosity & $\mu_{h n f}=\frac{1}{\left(1-\phi_{h n f}\right)^{2.5}}$ \\
$\begin{array}{l}\text { Thermal } \\
\text { conductivity }\end{array}$ & $\frac{k_{h n f}}{k_{f}}=\left[\frac{\left.\left(\frac{\phi_{1} k_{s 1}+\phi_{2} k_{s 2}}{\phi_{h n f}}\right)+2 k_{f}+2\left(\phi_{1} k_{s 1}+\phi_{2} k_{s 2}\right)-2 \phi_{h n f} k_{f}\right]}{\left.\left(\frac{\phi_{1} k_{s 1}+\phi_{2} k_{s 2}}{\phi_{h n f}}\right)+2 k_{f}-\left(\phi_{1} k_{s 1}+\phi_{2} k_{s 2}\right)+\phi_{h n f} k_{f}\right]}\right.$ \\
\hline
\end{tabular}

Now, we introduced

$$
\begin{gathered}
u=\frac{u_{0} x}{L(1-\beta t)} f^{\prime}(\eta), v=-\frac{a}{r} \sqrt{\frac{u_{0} v_{f}}{L(1-\beta t)}} f(\eta), \\
\theta(\eta)=\frac{T-T_{\infty}}{T_{w}-T_{\infty}}, \eta=\sqrt{\frac{u_{0}}{v_{f} L(1-\beta t)}}\left(\frac{r^{2}-a^{2}}{2 a}\right),
\end{gathered}
$$

hence $v=-\frac{a}{r} \sqrt{\frac{u_{0} v_{f}}{L(1-\beta t)}} S$.

The above similarity variables are employed to transform the partial differential equations by replacing Eq. (5) into Eq. (2)-(4), the resulting equations are formulated

$$
\begin{aligned}
& \frac{\mu_{h n f} / \mu_{f}}{\rho_{h n f} / \rho_{f}}\left[(1+2 \gamma \eta) f^{\prime \prime \prime}+2 \gamma f^{\prime \prime}\right]+\left(f-\frac{\varepsilon}{2} \eta\right) f^{\prime \prime}-\left(\varepsilon+f^{\prime}\right) f^{\prime}=0, \\
& \frac{1}{\operatorname{Pr}} \frac{k_{h n f} / k_{f}}{\left(\rho C_{p}\right)_{h n f} /\left(\rho C_{p}\right)_{f}}\left[(1+2 \gamma \eta) \theta^{\prime \prime}+2 \gamma \theta^{\prime}\right]+\left(f-\frac{\varepsilon}{2} \eta\right) \theta^{\prime}-2\left(\varepsilon+f^{\prime}\right) \theta=0,
\end{aligned}
$$

subject to the boundary conditions

$$
\begin{gathered}
f(0)=S, \quad f^{\prime}(0)=\lambda, \quad \theta(0)=1, \\
f^{\prime}(\eta) \rightarrow 0, \quad \theta(\eta) \rightarrow 0, \text { as } \eta \rightarrow \infty,
\end{gathered}
$$

where primes denote differentiation with respect to $\eta, \gamma=\sqrt{v_{f} L(1-\beta t) / u_{0} a^{2}}$ is the curvature parameter, $\operatorname{Pr}=\mu_{f} C_{p} / k_{f}$ is the Prandtl number, and $\varepsilon=\beta L / u_{0}$ represents the unsteadiness parameter. The physical quantities of concern are $C_{f}=\tau_{w} / \rho_{f} U_{w}{ }^{2}$, which is the skin friction 
coefficient and $\mathrm{Nu}_{\mathrm{x}}=\frac{x q_{w}}{k_{f}\left(T_{w}-T_{\infty}\right)}$ is the local Nusselt number. Here, $\tau_{w}=\mu_{h n f}\left(\frac{\partial u}{\partial r}\right)_{r=a}$ and $q_{w}=-k_{h n f}\left(\frac{\partial T}{\partial r}\right)_{r=a}$ are the skin friction coefficient and heat flux along the permeable shrinking/stretching cylinder, respectively. Using the information mentioned above, finally, we obtain:

$\operatorname{Re}_{x}^{1 / 2} C_{f}=\frac{\mu_{h n f}}{\mu_{f}} f^{\prime \prime}(0), \quad \operatorname{Re}_{x}^{-1 / 2} N u_{x}=-\frac{k_{h n f}}{k_{f}} \theta^{\prime}(0)$,

where $\operatorname{Re}_{x}=u_{0} x^{2} / v_{f} L(1-\beta t)$.

\section{Stability Analysis}

A stability analysis is implemented by perceiving the efforts of Merkin [29] and Merrill et al., [30] since the existence of dual solutions is confirmed in the boundary value problem (6) and (7). Now, a new conversion of similarity is proposed under the unsteady-state query

$$
\begin{gathered}
u=\frac{u_{0} x}{L(1-\beta t)} \frac{\partial f}{\partial \eta}(\eta, \tau), v=-\frac{a}{r} \sqrt{\frac{u_{0} v}{L(1-\beta t)}} f(\eta, \tau), \theta=\frac{T-T_{\infty}}{T_{w}-T_{\infty}}, \\
\eta=y \sqrt{\frac{u_{0}}{v_{f} L(1-\beta t)}}\left(\frac{r^{2}-a^{2}}{2 a}\right), \tau=\frac{u_{0} t}{L(1-\beta t)} .
\end{gathered}
$$

Employing Eq. (10) into Eq. (6) and Eq. (7), the following equations are secured

$$
\begin{aligned}
& \frac{\mu_{\text {hnf }} / \mu_{f}}{\rho_{\text {hnf }} / \rho_{f}}\left[(1+2 \gamma \eta) \frac{\partial^{3} f}{\partial \eta^{3}}+2 \gamma \frac{\partial^{2} f}{\partial \eta^{2}}\right]+\left(f-\frac{\varepsilon}{2} \eta\right) \frac{\partial^{2} f}{\partial \eta^{2}}-\left(\varepsilon+\frac{\partial f}{\partial \eta}\right) \frac{\partial f}{\partial \eta}-\frac{1}{(1+\beta \tau)} \frac{\partial^{2} f}{\partial \eta \partial \tau}=0, \\
& \frac{1}{\operatorname{Pr}}\left(\frac{K_{h n f} / K_{f}}{\left(\rho C_{p}\right)_{h n f} /\left(\rho C_{p}\right)_{f}}\right)\left[(1+2 \gamma \eta) \frac{\partial^{2} \theta}{\partial \eta^{2}}+2 \gamma \frac{\partial \theta}{\partial \eta}\right]+\left(f-\frac{\varepsilon}{2} \eta\right) \frac{\partial \theta}{\partial \eta}-2\left(\varepsilon+\frac{\partial f}{\partial \eta}\right) \theta \\
& -\frac{1}{(1+\beta \tau)} \frac{\partial \theta}{\partial \tau}=0,
\end{aligned}
$$

with respect to

$$
\begin{gathered}
f(0)=S, \quad \frac{\partial f}{\partial \eta}(0)=\lambda, \quad \theta(0)=1, \\
\frac{\partial f}{\partial \eta}(\eta) \rightarrow 0, \quad \theta(\eta) \rightarrow 0,
\end{gathered}
$$

Consistent with the idea by Weidman et al., [31] to scrutinise the steady flow stability $f(\eta)=f_{0}(\eta)$ and $\theta(\eta)=\theta_{0}(\eta)$, we write 


$$
\begin{aligned}
& f(\eta, \tau)=f_{0}(\eta)+e^{-\omega \tau} F(\eta), \\
& \theta(\eta, \tau)=\theta_{0}(\eta)+e^{-\omega \tau} G(\eta),
\end{aligned}
$$

where $\omega$ is the undetermined eigenvalue parameter, while $F(\eta)$ and $G(\eta)$ are relatively small to $f_{0}(\eta)$ and $\theta_{0}(\eta)$. The eigenvalue problem (11) and (12) results in an infinite group of eigenvalues $\omega_{1}<\omega_{2}<\omega_{3} \ldots$ that detect a stable flow and early decay when $\omega_{1}$ is positive. In contrast, when $\omega_{1}$ is negative, early growth of perturbations is detected, revealing the erratic flow. Substituting Eq. (14) into Eq. (11) and Eq. (12), we have

$$
\begin{gathered}
\frac{\mu_{h n f} / \mu_{f}}{\rho_{h n f} / \rho_{f}}\left[(1+2 \gamma \eta) \frac{\partial^{3} F}{\partial \eta^{3}}+2 \gamma \frac{\partial^{2} F}{\partial \eta^{2}}\right]+\left(f_{0}-\frac{\varepsilon}{2} \eta\right) \frac{\partial^{2} F}{\partial \eta^{2}}-F \frac{\partial^{2} f_{0}}{\partial \eta^{2}}-2 \frac{\partial f_{0}}{\partial \eta} \frac{\partial F}{\partial \eta}+(\omega-\varepsilon) \frac{\partial F}{\partial \eta}=0, \\
\frac{1}{\operatorname{Pr}\left(\frac{K_{h n f} / K_{f}}{\left(\rho C_{p}\right)_{h n f} /\left(\rho C_{p}\right)_{f}}\right)}\left[(1+2 \gamma \eta) \frac{\partial^{2} G}{\partial \eta^{2}}+2 \gamma \frac{\partial G}{\partial \eta}\right]+\left(f_{0}-\frac{\varepsilon}{2} \eta\right) \frac{\partial G}{\partial \eta}+F\left(\frac{\partial \theta_{0}}{\partial \eta}\right) \\
-2\left(\varepsilon G+G \frac{\partial f_{0}}{\partial \eta}+\theta \frac{\partial F}{\partial \eta}\right)+\omega G=0,
\end{gathered}
$$

and the boundary conditions are as follows

$$
\begin{gathered}
F(0, \tau)=0, \quad \frac{\partial F}{\partial \eta}(0, \tau)=0, \quad G(0, \tau)=0, \\
\frac{\partial F}{\partial \eta}(\eta) \rightarrow 0, \quad G(\eta) \rightarrow 0,
\end{gathered}
$$

The steady-state flow solutions, in example, $f_{0}(\eta)$ and $\theta_{0}(\eta)$ were implemented via $\tau \rightarrow 0$. Consequently, the resulting linearised eigenvalue problem is determined

$$
\begin{aligned}
& \frac{\mu_{h n f} / \mu_{f}}{\rho_{h n f} / \rho_{f}}\left[(1+2 \gamma \eta) F^{\prime \prime \prime}+2 \gamma F^{\prime \prime}\right]+\left(f_{0}-\frac{\varepsilon}{2} \eta\right) F^{\prime \prime}-F f_{0}^{\prime \prime}-2 f_{0}^{\prime} F^{\prime}+(\omega-\varepsilon) F^{\prime}=0 \\
& \frac{1}{\operatorname{Pr}}\left(\frac{K_{h n f} / K_{f}}{\left(\rho C_{p}\right)_{h n f} /\left(\rho C_{p}\right)_{f}}\right)\left[(1+2 \gamma \eta) G^{\prime \prime}+2 \gamma G^{\prime}\right]+\left(f_{0}-\frac{\varepsilon}{2} \eta\right) G^{\prime}+F \theta_{0}^{\prime} \\
& -2\left(\varepsilon G+G f_{0}^{\prime}+\theta F^{\prime}\right)+\omega G=0 \\
& F(0, \tau)=0, \quad F^{\prime}(0, \tau)=0, \quad G(0, \tau)=0, \\
& F^{\prime}(\eta) \rightarrow 0, \quad G(\eta) \rightarrow 0 \quad \text { as } \quad \eta \rightarrow \infty,
\end{aligned}
$$

The achievable eigenvalues could be deliberated via relaxing a boundary condition [32]. In the current analysis, we set $F^{\prime}(\eta) \rightarrow 0$ hence the linearised eigenvalue problems (18)-(20) are revealed as $F^{\prime \prime}(0)=1$ when $\omega_{1}$ is fixed. 


\section{Results and Discussions}

The resulting nonlinear ordinary differential equations presented in Eq. (6)-(8) can be solved numerically using the bvp4c function in MATLAB software. Typically, the use of multiple initial guess values provides more than one solution. The significance of the present results is evaluated with Khashi'ie et al., [20] and Waini et al., [33], who performed the numerical analysis by using the bvp4c technique, while Devi and Devi [34] employed the Runge-Kutta-Fehlberg integration method along with the Nachtsheim-Swigert shooting iteration technique. Noticeably, the current results correspond remarkably to the previous literature, as shown in Table 3.

Table 3

Approximation values of $\operatorname{Re}_{x}^{1 / 2} C_{f}$ by certain values of $\phi_{2}$ when

\begin{tabular}{lllll}
\multicolumn{5}{l}{$\varepsilon=\gamma=S=0, \phi_{1}=0.1, \lambda=1$ and $\operatorname{Pr}=6.135$} \\
$\phi_{2}$ & Present result & Khashi'ie et al., [20] & Waini et al., [33] & Devi and Devi [34] \\
\hline 0.005 & -1.328754 & -1.327098 & -1.327098 & -1.327310 \\
0.02 & -1.416377 & -1.409490 & -1.409490 & -1.409683 \\
0.04 & -1.535214 & -1.520721 & -1.520721 & -1.520894 \\
0.06 & -1.657219 & -1.634119 & -1.634119 & -1.634279 \\
\hline
\end{tabular}

Figure 2 and Figure 3 describe the effect of the suction parameter $S$ on the skin friction coefficient $f^{\prime \prime}(0)$ and heat transfer rate $-\theta^{\prime}(0)$ past a permeable stretching/shrinking cylinder in $\mathrm{Al}_{2} \mathrm{O}_{3}-\mathrm{Cu} / \mathrm{H}_{2} \mathrm{O}$. More than one solution is documented in the shrinking $(\lambda<0)$ cylinder, while a unique solution can be observed as the cylinder stretches $(\lambda>0)$. Figure 2 reveals that an increment in $S$ will conclusively boosts $f^{\prime \prime}(0)$ in the first solution. The suction phenomenon on a permeable stretching/shrinking cylinder will potentially promote stability of the boundary layer. Subsequently, the suction lowers the pressure in such an outward flow on the bodies, thereby reducing the boundary layer thickness and accentuating the velocity gradient of the permeable cylinder by evacuating the fluid alongside the surface with low momentum. The first solution conveys an augmentation in $-\theta^{\prime}(0)$ as $S$ escalates through the permeable cylindrical surface, as demonstrated in Figure 3. Note that the suction effect authorises the hybrid $\mathrm{Al}_{2} \mathrm{O}_{3}-\mathrm{Cu} / \mathrm{H}_{2} \mathrm{O}$ nanofluid molecules to dominate the cylindrical surface and then literally improve the heat transfer performance.

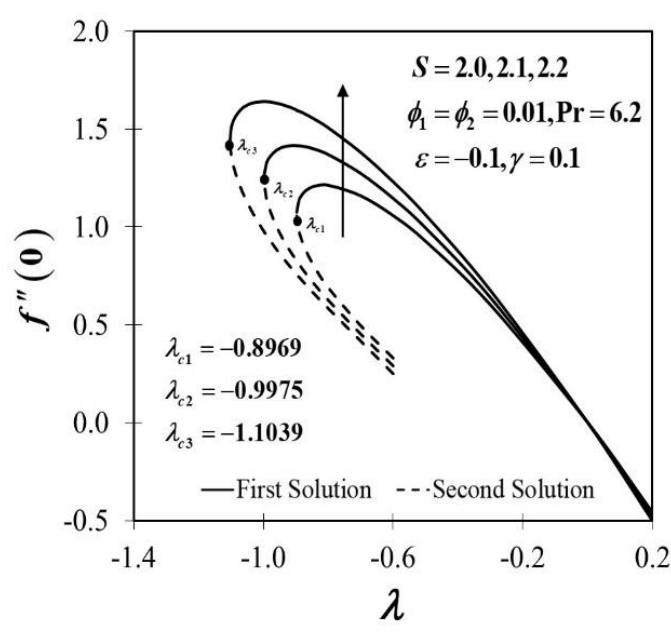

Fig. 2. $f^{\prime \prime}(0)$ against $\lambda$ by various $S$

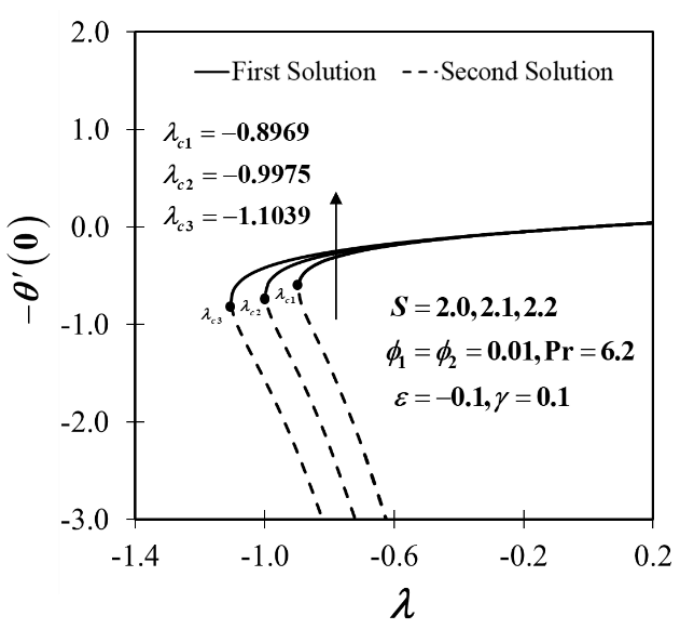

Fig. 3. $-\theta^{\prime}(0)$ against $\lambda$ by various $S$ 
Figure 4 and Figure 5 depict the variants of velocity $f^{\prime}(\eta)$ and temperature distribution profiles $\theta(\eta)$ when $S$ varied. All profiles clearly satisfy the far-field boundary conditions (8) asymptotically when $\eta_{\infty}=15$ is executed. This encourages the relevance of the results obtained and also supporting the existence of the dual solution. Additionally, $f^{\prime}(\eta)$ increases in the first solution when $S$ improves while decreases in the second solution, as presented in Figure 4. Also, it is noted that the thickness of the boundary layer decreases with the addition of $S$ in the first solution, while this result shows an opposite trend in the second solution. This may have been due to the occurrence of the backward flow on the permeable shrinking cylinder, resulting in reversing patterns of the second solution. The variants of $\theta(\eta)$ in the hybrid $\mathrm{Al}_{2} \mathrm{O}_{3}-\mathrm{Cu} / \mathrm{H}_{2} \mathrm{O}$ nanofluid over a permeable shrinking cylinder is displayed in Figure 5 . The analysis supports the results obtained in Figure 3, which portrays the reduction trend in the temperature distributions as $S$ improves. The decrease in the hybrid $\mathrm{Al}_{2} \mathrm{O}_{3}-\mathrm{Cu} / \mathrm{H}_{2} \mathrm{O}$ nanofluid temperature reduces the hybrid nanofluid's thermal conductivity and gradually increases the heat transfer performance.



Fig. 4. $f^{\prime}(\eta)$ with $S=2.0,2.1,2.2$

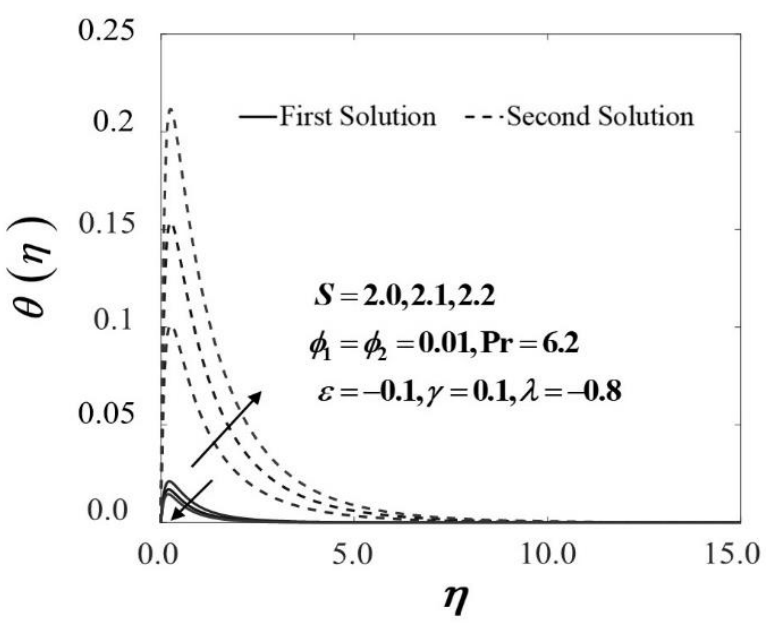

Fig. 5. $\theta(\eta)$ with $S=2.0,2.1,2.2$

Figure 6 and Figure 7 display the decrement in the first solution for both $f^{\prime \prime}(0)$ and $-\theta^{\prime}(0)$ against $S$ when the unsteadiness parameter $\varepsilon$ decreases. Figure 6 captures that as $\varepsilon$ reduced, the first solution has declined in $f^{\prime \prime}(0)$ whereas a reversal result is shown in the second solution. The reduction in $\varepsilon$ corresponds to the boundary layer thickness extension and reduces the velocity gradient of the permeable shrinking cylinder; hence $f^{\prime \prime}(0)$ dropped. The total sum of nanoparticle volume fraction $\left(\phi_{1}=\phi_{1}=0.01\right)$, which equals to $2 \%$, may also trigger the reduction of $f^{\prime \prime}(0)$ due to the upsurge in the viscosity of hybrid nanofluids past the shrinking cylinder. Furthermore, according to the outcomes produced in Figure $7,-\theta^{\prime}(0)$ is diminished in the first solution while $\varepsilon$ reduced. From the present evidence, the authors may summarise that $\varepsilon$ significantly facilitates the degradation of heat transfer in the shrinking cylinder. Even then, if several regulatory parameters are taken into account, the authors would also like to advise that these outcomes may vary. 


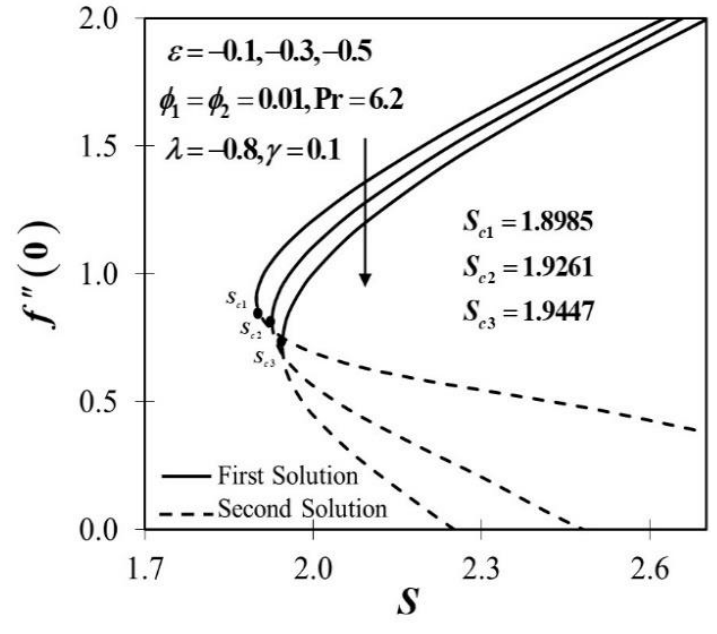

Fig. 6. $f^{\prime \prime}(0)$ against $S$ by various $\varepsilon$



Fig. 7. $-\theta^{\prime}(0)$ against $S$ by various $\varepsilon$

On the other note, Figure 8 and Figure 9 are prepared to demonstrate the impact of $\varepsilon$ toward $f^{\prime}(\eta)$ and $-\theta^{\prime}(0)$, respectively. As exemplified in Figure 8 , the first solution diminishes in response to the declining of $\varepsilon$, whereas the second solution revealed contradictory outcomes. The temperature profiles, $\theta(\eta)$ in Figure 9 support the trend seen in Figure 7, which demonstrates the changes in temperature as $\varepsilon$ decreased.

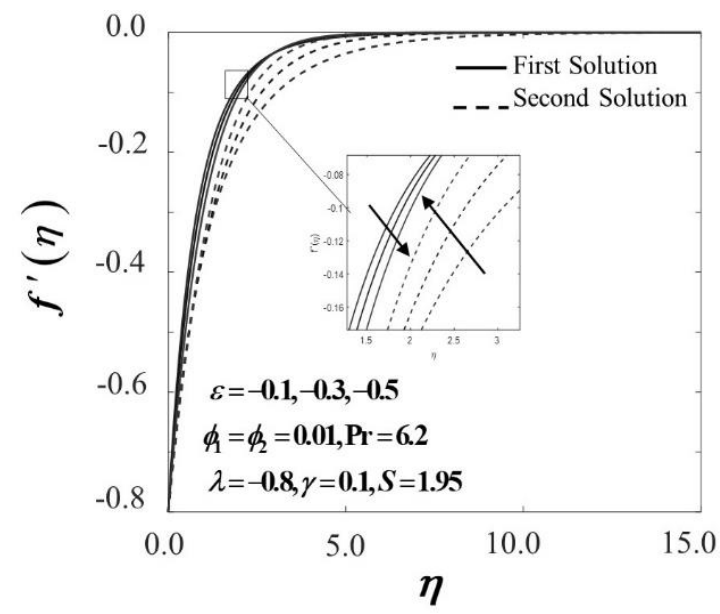

Fig. 8. $f^{\prime}(\eta)$ with $\varepsilon=-0.1,-0.3,-0.5$



Fig. 9. $\theta(\eta)$ with $\varepsilon=-0.1,-0.3,-0.5$

Finally, a stability analysis was further carried out and presented in Table 4. The smallest eigenvalues $\omega_{1}$ with positive value elucidate the property of the solution stability to resolve the permitting disturbances. Thus, the flow is stable. It also suggests an early deterioration in the appearance of disruptions. Meanwhile, when $\omega_{1}$ appears negative, the flow is represented unstable as it evokes an initial extension of interruptions. 


\section{Table 4}

The smallest eigenvalues, $\omega_{1}$ with assorted $\lambda$

\begin{tabular}{lll}
\hline$\lambda$ & First solution $\omega_{1}$ & Second solution $\omega_{1}$ \\
\hline-1 & 0.4044 & -0.3799 \\
-1.1 & 0.2835 & -0.1848 \\
-1.101 & 0.2803 & -0.1775 \\
-1.103 & 0.2718 & -0.1573 \\
-1.1039 & 0.2642 & -0.1385 \\
\hline
\end{tabular}

\section{Conclusion}

This study explores the impact of suction and unsteadiness parameters in hybrid nanofluid over a permeable shrinking cylinder. More than one solution is visible when the cylindrical surface shrunk. An augmentation in the suction parameter promotes boundary-layer stability and also improving heat conductivity. A reduction in the unsteadiness parameter reduces the coefficient of skin friction with the opposing flow over the permeable shrinking cylinder. Further, the local Nusselt number outcomes conclude that the unsteadiness parameter strongly encourages the heat transfer deterioration in the permeable shrinking cylinder. Eventually, the stability analysis is performed since the dual solutions are proven to exist. The analysis of solution stability has confirmed the steadiness and constancy of the first solution, whereas the second solution is unconvincing and unstable.

\section{Acknowledgements}

The work is supported by the MoHE's research grant (FRGS/1/2020/STG06/UKM/01/1).

\section{References}

[1] Choi, S. US, and Jeffrey A. Eastman. Enhancing thermal conductivity of fluids with nanoparticles. No. ANL/MSD/CP84938; CONF-951135-29. Argonne National Lab., IL (United States), 1995.

[2] Das, Pritam Kumar. "A review based on the effect and mechanism of thermal conductivity of normal nanofluids and hybrid nanofluids." Journal of Molecular Liquids 240 (2017): 420-446. https://doi.org/10.1016/i.molliq.2017.05.071

[3] Hamzah, Muhammad Hafiz, Nor Azwadi Che Sidik, Tan Lit Ken, Rizalman Mamat, and G. Najafi. "Factors affecting the performance of hybrid nanofluids: a comprehensive review." International Journal of Heat and Mass Transfer 115 (2017): 630-646. https://doi.org/10.1016/j.ijheatmasstransfer.2017.07.021

[4] Zainal, Nurul Amira, Roslinda Nazar, Kohilavani Naganthran, and Ioan Pop. "Stability analysis of MHD hybrid nanofluid flow over a stretching/shrinking sheet with quadratic velocity." Alexandria Engineering Journal 60, no. 1 (2021): 915-926. https://doi.org/10.1016/j.aej.2020.10.020

[5] Zainal, N. A., R. Nazar, K. Naganthran, and I. Pop. "Impact of anisotropic slip on the stagnation-point flow past a stretching/shrinking surface of the Al2O3-Cu/H2O hybrid nanofluid." Applied Mathematics and Mechanics 41, no. 9 (2020): 1401-1416. https://doi.org/10.1007/s10483-020-2642-6

[6] Waini, Iskandar, Anuar Ishak, and Ioan Pop. "Mixed convection flow over an exponentially stretching/shrinking vertical surface in a hybrid nanofluid." Alexandria Engineering Journal 59, no. 3 (2020): 1881-1891. https://doi.org/10.1016/i.aej.2020.05.030

[7] Waini, Iskandar, Anuar Ishak, and loan Pop. "Hybrid nanofluid flow towards a stagnation point on a stretching/shrinking cylinder." Scientific Reports 10, no. 1 (2020): 1-12. https://doi.org/10.1038/s41598-02066126-2

[8] Jamaludin, Anuar, Kohilavani Naganthran, Roslinda Nazar, and loan Pop. "MHD mixed convection stagnation-point flow of Cu-Al2O3/water hybrid nanofluid over a permeable stretching/shrinking surface with heat source/sink." European Journal of Mechanics-B/Fluids 84 (2020): 71-80. https://doi.org/10.1016/i.euromechflu.2020.05.017

[9] Khashi'ie, Najiyah Safwa, Ezad Hafidz Hafidzuddin, Norihan Md Arifin, and Nadihah Wahi. "Stagnation point flow of hybrid nanofluid over a permeable vertical stretching/shrinking cylinder with thermal stratification effect." CFD Letters 12, no. 2 (2020): 80-94.

[10] Smith, F. T. "Steady and unsteady boundary-layer separation." Annual Review of Fluid Mechanics 18, no. 1 (1986): 197-220. https://doi.org/10.1146/annurev.fl.18.010186.001213 
[11] White, Frank M. Viscous fluid flow. McGraw-Hill, New York (1991).

[12] McCroskey, William J. "Current Research in Unsteady Fluid Dynamics-The 1976 Freeman Scholar Lecture, Trans. ASME." J. Fluid Eng. 1 (1977): 8-39. https://doi.org/10.1115/1.3448570

[13] Tie-Gang, Fang, Zhang Ji, Zhong Yong-Fang, and Tao Hua. "Unsteady viscous flow over an expanding stretching cylinder." Chinese Physics Letters 28, no. 12 (2011): 124707. https://doi.org/10.1088/0256-307X/28/12/124707

[14] Ramesh, G. K., K. Ganesh Kumar, B. J. Gireesha, S. A. Shehzad, and F. M. Abbasi. "Magnetohydrodynamic nanoliquid due to unsteady contracting cylinder with uniform heat generation/absorption and convective condition." Alexandria Engineering Journal 57, no. 4 (2018): 3333-3340. https://doi.org/10.1016/i.aej.2017.12.009

[15] Tabassum, G. D., A. Mehmood, M. Usman, and A. Dar. "Multiple Solutions for an Unsteady Stretching Cylinder." Journal of Applied Mechanics and Technical Physics 61, no. 3 (2020): 439-446. https://doi.org/10.1134/S0021894420030165

[16] Ganesan, P., and P. Loganathan. "Magnetic field effect on a moving vertical cylinder with constant heat flux." Heat and Mass Transfer 39, no. 5 (2003): 381-386. https://doi.org/10.1007/s00231-002-0383-y

[17] Buchlin, Jean-Marie. "Natural and forced convective heat transfer on slender cylinders." Revue générale de Thermique 37, no. 8 (1998): 653-660. https://doi.org/10.1016/S0035-3159(98)80043-3

[18] Datta, Prabal, D. Anilkumar, S. Roy, and N. C. Mahanti. "Effect of non-uniform slot injection (suction) on a forced flow over a slender cylinder." International Journal of Heat and Mass Transfer 49, no. 13-14 (2006): $2366-2371$. https://doi.org/10.1016/j.ijheatmasstransfer.2005.10.044

[19] Kumari, M., and G. Nath. "Mixed convection boundary layer flow over a thin vertical cylinder with localized injection/suction and cooling/heating." International Journal of Heat and Mass Transfer 47, no. 5 (2004): $969-976$. https://doi.org/10.1016/j.ijheatmasstransfer.2003.08.014

[20] Khashi'ie, Najiyah Safwa, Norihan Md Arifin, Ioan Pop, and Nur Syahirah Wahid. "Flow and heat transfer of hybrid nanofluid over a permeable shrinking cylinder with Joule heating: a comparative analysis." Alexandria Engineering Journal 59, no. 3 (2020): 1787-1798. https://doi.org/10.1016/i.aej.2020.04.048

[21] Khashi'ie, Najiyah Safwa, Iskandar Waini, Nurul Amira Zainal, Khairum Hamzah, and Abdul Rahman Mohd Kasim. "Hybrid Nanofluid Flow Past a Shrinking Cylinder with Prescribed Surface Heat Flux." Symmetry 12, no. 9 (2020): 1493. https://doi.org/10.3390/sym12091493

[22] Butt, Adnan Saeed, and Asif Ali. "Entropy analysis of magnetohydrodynamic flow and heat transfer due to a stretching cylinder." Journal of the Taiwan Institute of Chemical Engineers 45, no. 3 (2014): 780-786. https://doi.org/10.1016/i.jtice.2013.08.018

[23] Khashi'ie, Najiyah Safwa, Norihan Md Arifin, Ezad Hafidz Hafidzuddin, and Nadihah Wahi. "Thermally stratified flow of Cu-Al2O3/water hybrid nanofluid past a permeable stretching/shrinking circular cylinder." Journal of Advanced Research in Fluid Mechanics and Thermal Sciences 63, no. 1 (2019): 154-163.

[24] Mohamed, Muhammad Khairul Anuar, N. A. Z. M. Noar, Mohd Zuki Salleh, and Anuar Ishak. "Free convection boundary layer flow on a horizontal circular cylinder in a nanofluid with viscous dissipation." Sains Malaysiana 45, no. 2 (2016): 289-296.

[25] Zainal, Nurul Amira, Roslinda Nazar, Kohilavani Naganthran, and Ioan Pop. "Unsteady Stagnation Point Flow of Hybrid Nanofluid Past a Convectively Heated Stretching/Shrinking Sheet with Velocity Slip." Mathematics 8 , no. 10 (2020): 1649. https://doi.org/10.3390/math8101649

[26] Abu-Nada, Eiyad, and Hakan F. Oztop. "Effects of inclination angle on natural convection in enclosures filled with Cu-water nanofluid." International Journal of Heat and Fluid Flow 30, no. 4 (2009): 669-678. https://doi.org/10.1016/i.ijheatfluidflow.2009.02.001

[27] Ghalambaz, Mohammad, Natalia C. Roşca, Alin V. Roşca, and loan Pop. "Mixed convection and stability analysis of stagnation-point boundary layer flow and heat transfer of hybrid nanofluids over a vertical plate." International Journal of Numerical Methods for Heat \& Fluid Flow 30, no. 7 (2019): 3737-3754. https://doi.org/10.1108/HFF-08$\underline{2019-0661}$

[28] Takabi, Behrouz, and Saeed Salehi. "Augmentation of the heat transfer performance of a sinusoidal corrugated enclosure by employing hybrid nanofluid." Advances in Mechanical Engineering 6 (2014): 147059. https://doi.org/10.1155/2014/147059

[29] Merkin, J. H. "Mixed convection boundary layer flow on a vertical surface in a saturated porous medium." Journal of Engineering Mathematics 14, no. 4 (1980): 301-313. https://doi.org/10.1007/BF00052913

[30] Merrill, Keith, Matthew Beauchesne, Joseph Previte, Joseph Paullet, and Patrick Weidman. "Final steady flow near a stagnation point on a vertical surface in a porous medium." International Journal of Heat and Mass Transfer 49, no. 23-24 (2006): 4681-4686. https://doi.org/10.1016/j.ijheatmasstransfer.2006.02.056

[31] Weidman, P. D., D. G. Kubitschek, and A. M. J. Davis. "The effect of transpiration on self-similar boundary layer flow over moving surfaces." International Journal of Engineering Science 44, no. $11-12$ (2006): $730-737$. https://doi.org/10.1016/j.ijengsci.2006.04.005 
[32] Harris, S. D., D. B. Ingham, and I. Pop. "Mixed convection boundary-layer flow near the stagnation point on a vertical surface in a porous medium: Brinkman model with slip." Transport in Porous Media 77, no. 2 (2009): $267-285$. https://doi.org/10.1007/s11242-008-9309-6

[33] Waini, Iskandar, Anuar Ishak, and loan Pop. "Unsteady flow and heat transfer past a stretching/shrinking sheet in a hybrid nanofluid." International Journal of Heat and Mass Transfer 136 (2019): 288-297. https://doi.org/10.1016/i.ijheatmasstransfer.2019.02.101

[34] Devi, Suriya Uma, and SP Anjali Devi. "Heat transfer enhancement of Cu-Al2O3/water hybrid nanofluid flow over a stretching sheet." Journal of the Nigerian Mathematical Society 36, no. 2 (2017): 419-433. 